\title{
Glaucoma: a brief update for 2017
}

\section{Natalie Schellack, ${ }^{1}$ Gustav Schellack, ${ }^{2}$ Selente Bezuidenhout, ${ }^{1}$ Lucille Malan, ${ }^{1}$ Hanneke de Klerk ${ }^{1}$}

'School of Pharmacy, Sefako Makgatho Health Sciences University

${ }^{2}$ Clinical research professional in the private sector

\section{Corresponding author, email: natalie.schellack@smu.ac.za}

\section{Abstract}

Glaucoma is a complex condition of the eye and the second leading cause of blindness around the globe. It is an ophthalmic neurodegenerative condition and is characterised by a raised intra-ocular pressure (IOP). The latter also constitutes the only modifiable risk factor in glaucoma management. When left untreated patients may gradually experience a visual field loss, and even lose their sight completely. This article provides a brief overview of this condition, the pharmacological treatment options that are available in South Africa, as well as the rational use thereof.

Keywords: glaucoma, intra-ocular pressure, IOP, ocular hypertension, visual field loss, carbonic anhydrase

\section{Introduction}

Glaucoma is progressive optic neuropathy that affects the eye and is associated with an increased intra-ocular pressure (IOP), which also constitutes the only modifiable risk factor in glaucoma management. When left untreated patients may gradually experience a visual field loss, and even lose their sight completely. It is the number one cause of irreversible vision loss and the second leading cause of blindness around the globe. ${ }^{1,2}$

Glaucoma may be defined as a condition that causes progressive neuropathy in the optic field that is characterised by structural changes in the optic nerve head (or optic disk). This may lead to functional changes in the patients' visual field, when no other ocular diseases or congenital abnormalities could be found. ${ }^{3}$

Around 66.8 million people worldwide are afflicted with glaucoma. Predictions are that glaucoma will affect almost 80 million people by $2020^{4}$ and 111.8 million people by 2040, affecting more people residing in Asia and Africa. ${ }^{5}$ The estimated prevalence of glaucoma is around 5 to $7 \%$ in the black population and 3 to $5 \%$ in the white population of South Africa. A total of approximately 200000 people are currently affected by glaucoma in South Africa. ${ }^{6}$ There are different variations of glaucoma but the two major types are listed in Table I.

\section{Pathophysiology and classification}

The pathophysiology of glaucoma is not completely understood, but is related to retinal ganglion cell death. A better understanding of the pathophysiological mechanisms involved in the onset and progression of glaucomatous optic neuropathy is crucial in the development of better therapeutic options. ${ }^{8}$ The
Table I: Major types of glaucoma

\begin{tabular}{ll}
\hline Open-angle glaucoma (OAG) & Angle-closure glaucoma (ACG)* \\
\hline $\begin{array}{l}\text { Accounts for at least } 90 \% \text { of all } \\
\text { glaucoma cases }\end{array}$ & Less common form of glaucoma \\
$\begin{array}{l}\text { Caused by the slow clogging of } \\
\text { the drainage canals, resulting in } \\
\text { increased intraocular pressure }\end{array}$ & Develops very quickly \\
$\begin{array}{ll}\text { Has a wide and open angle } \\
\text { between the iris and cornea }\end{array}$ & $\begin{array}{l}\text { Has a closed or narrow angle } \\
\text { between the iris and cornea }\end{array}$ \\
$\begin{array}{ll}\text { Has symptoms and damage that } \\
\text { are not readily noticed }\end{array}$ & $\begin{array}{l}\text { Has symptoms and damage that } \\
\text { are usually very noticeable }\end{array}$ \\
\hline
\end{tabular}

*Also known as closed-angle or narrow-angle glaucoma

normal physiological balance between the secretion of aqueous humour and the drainage thereof is affected by this condition. Aqueous humour is secreted by the ciliary body and drainage of the humour takes place via two independent pathways, namely the trabecular meshwork and the uveoscleral outflow pathway..$^{9,10}$

The filtration is dependent on pressure gradients, blood pressure and increased IOP. Osmotic gradients produced by the active secretion of sodium and bicarbonate ions and other solutes, produce a pressure gradient that allows for the movement of the humour from the pool of ciliary stromal ultrafiltrate into the posterior chamber, thereby forming aqueous humour. Various receptors and transmitters are found in the ciliary epithelium and the smooth muscle structures of the eye. Carbonic anhydrase (primarily of the type II isozyme), aand $\beta$-adrenergic receptors, sodium and potassium-activated triphosphates, prostaglandins and muscarinic receptors all play a role in the normal functioning of the eye. Glaucoma can 
Table II: Classification of glaucoma-10

\begin{tabular}{ll}
\hline Primary glaucoma & Secondary glaucoma \\
\hline - Open-angle & Open-angle \\
- Angle-closure & $\circ$ Pre-trabecular \\
$\circ$ With pupillary block & $\circ$ Trabecular \\
$\circ$ Without pupillary block & $\circ$ Post-trabecular \\
& Angle-closure \\
& $\circ$ With pupillary block \\
& $\circ$ Without pupillary block \\
\hline
\end{tabular}

be classified as either a primary inherited disorder, secondary to a disease, trauma or drugs, or as being congenital in nature (Table II). ${ }^{9,10}$

Open-angle glaucoma may result from optic nerve damage at any range of intra-ocular pressure. The rate of progression can be either fast or slow, with patients who may have had increased intra-ocular pressures and then only present with changes in the optic disk or visual fields at a much later stage. This increases the challenge to diagnose and treat open-angle glaucoma, because the early disease is often asymptomatic. ${ }^{9-12}$

Closed-angle glaucoma may be due to a physical blockage of the trabecular meshwork. This can be more acute in onset. When the IOP is $>40 \mathrm{mmHg}$ optic nerve damage and even permanent nerve damage ( $>60 \mathrm{mmHg}$ ) can occur. However, since the trabecular meshwork is intrinsically normal, it is possible to restore the trabecular function by early removal of the synechiae before irreversible ultra-structural changes have occurred. ${ }^{9-11,13}$

Medicine-induced glaucoma may be due to an increased intraocular pressure brought about by various medicines. Medicines may worsen pre-existing glaucoma or induce glaucoma based on their mechanisms of action, and patients' predisposition. Table III provides an overview of medicines that may induce or potentiate an increased intraocular pressure:-11,14-17

Table III: Drugs that may potentiate or induce raised intraocular pressure in ${ }^{9-11,14-18}$

\begin{tabular}{ll}
\hline IOP & Mechanism \\
\hline $\begin{array}{l}\text { Ophthalmic corticosteroids } \\
\text { (high risk) }\end{array}$ & $\begin{array}{l}\text { Glucocorticosteroids reduce the } \\
\text { facilitation of aqueous humour } \\
\text { Systemic corticosteroids }\end{array}$ \\
$\begin{array}{l}\text { outflow through the trabecular } \\
\text { meshwork. Accumulation of the }\end{array}$ \\
extracellular material blocks the \\
trabecular channels and thus the \\
outflow.
\end{tabular}

$\begin{array}{ll}\text { Fenoldopam } & \begin{array}{l}\text { Through dopamine-1 receptor- } \\ \text { mediated effects, an increase in } \\ \text { intraocular pressure is observed } \\ \text { in both healthy volunteers and } \\ \text { patients with accelerated systemic } \\ \text { hypertension. }\end{array} \\ \begin{array}{ll}\text { Produce a rise in intraocular } \\ \text { agents }\end{array} & \begin{array}{l}\text { pressure } \\ \text { Vuccinylcholine }\end{array} \\ & \begin{array}{l}\text { Vian unknown mechanism } \\ \text { intraocular pressure by 5-10 } \mathrm{mmHg}\end{array} \\ & \text { for 5-10 minutes, with an onset of } \\ 2-4 \text { minutes after administration. }\end{array}$

\begin{tabular}{|c|c|}
\hline Vasodilators (low risk) & $\begin{array}{l}\text { For example, nitro-glycerine } \\
\text { used to treat acute angina may } \\
\text { cause visual blurring, increases } \\
\text { intra-ocular pressure, vasodilation } \\
\text { and a coloured halo, albeit in rare } \\
\text { instances. }\end{array}$ \\
\hline $\begin{array}{l}\text { Cimetidine and ranitidine (low } \\
\text { risk) }\end{array}$ & $\begin{array}{l}\text { These medicines have weak } \\
\text { anticholinergic side-effects, thus } \\
\text { raising the intraocular pressure. }\end{array}$ \\
\hline Closed-angle glaucoma & Mechanism \\
\hline $\begin{array}{l}\text { Topical sympathomimetics } \\
\text { Systemic anticholinergics } \\
\text { Systemic sympathomimetics } \\
\text { (low risk) }\end{array}$ & $\begin{array}{l}\text { Medicines that stimulate the } \\
\text { sympathomimetic system or inhibit } \\
\text { the parasympathomimetic system } \\
\text { cause pupillary dilatation, thus } \\
\text { precipitating acute angle-closures } \\
\text { in patients with occlusive anterior } \\
\text { chamber angles. }\end{array}$ \\
\hline
\end{tabular}

Heterocyclic antidepressants Cause acute angle closures, either Selective serotonin reuptake due to the indirect anticholinergic inhibitors (SSRIs) effects or increased levels of serotonin causing mydriasis.

Imipramine

Venlafaxine

Low-potency phenothiazines

Due to the inhibition of the parasympathomimetic system

\begin{tabular}{|ll}
\hline Antihistamines & $\begin{array}{l}\text { Due to the weak anticholinergic } \\
\text { effects }\end{array}$ \\
\hline Ipratropium bromide & $\begin{array}{l}\text { Anticholinergic effects causing } \\
\text { dilatation of the pupil and leading } \\
\text { to closure of the anterior chamber } \\
\text { drainage angles. }\end{array}$ \\
\hline Benzodiazepines (low risk) & $\begin{array}{l}\text { Induces relaxation of the sphincter } \\
\text { muscle of the iris and have a mild } \\
\text { anticholinergic effect }\end{array}$ \\
\hline $\begin{array}{l}\text { Methylxanthines (e.g. } \\
\text { theophylline and caffeine (low } \\
\text { risk)) }\end{array}$ & $\begin{array}{l}\text { The methylxanthines may } \\
\text { precipitate an attack of } \\
\text { angle-closure glaucoma, by } \\
\text { accentuating the anti-cholinergic } \\
\text { action on the eye. }\end{array}$ \\
\hline
\end{tabular}

Sulpha-containing medications May involve different mechanisms, including anterior rotation of the ciliary body with or without choroidal effusions, which result in a shallow anterior chamber and blockage of the trabecular meshwork by the iris. The exact reason for ciliary body swelling is unknown but it occurs in susceptible individuals. Topiramate is a sulpha-containing anticonvulsant. Some cases have been reported with topiramate having induced an acute angle-closure.

Tetracyclines (low risk) The mechanism may involve anterior rotation of the ciliary body with choroidal expansion, secondary to the accumulation of serous fluid in the extravascular choroidal space, causing closedangle glaucoma.

Monoamine oxidase inhibitors Cause a pupillary dilatation with (low risk) subsequent obstruction of the trabecular meshwork, and a possible increase in inflow during the papillary dilatation. 
Figure 1. Clinical presentation of glaucoma $2,9,10,19$

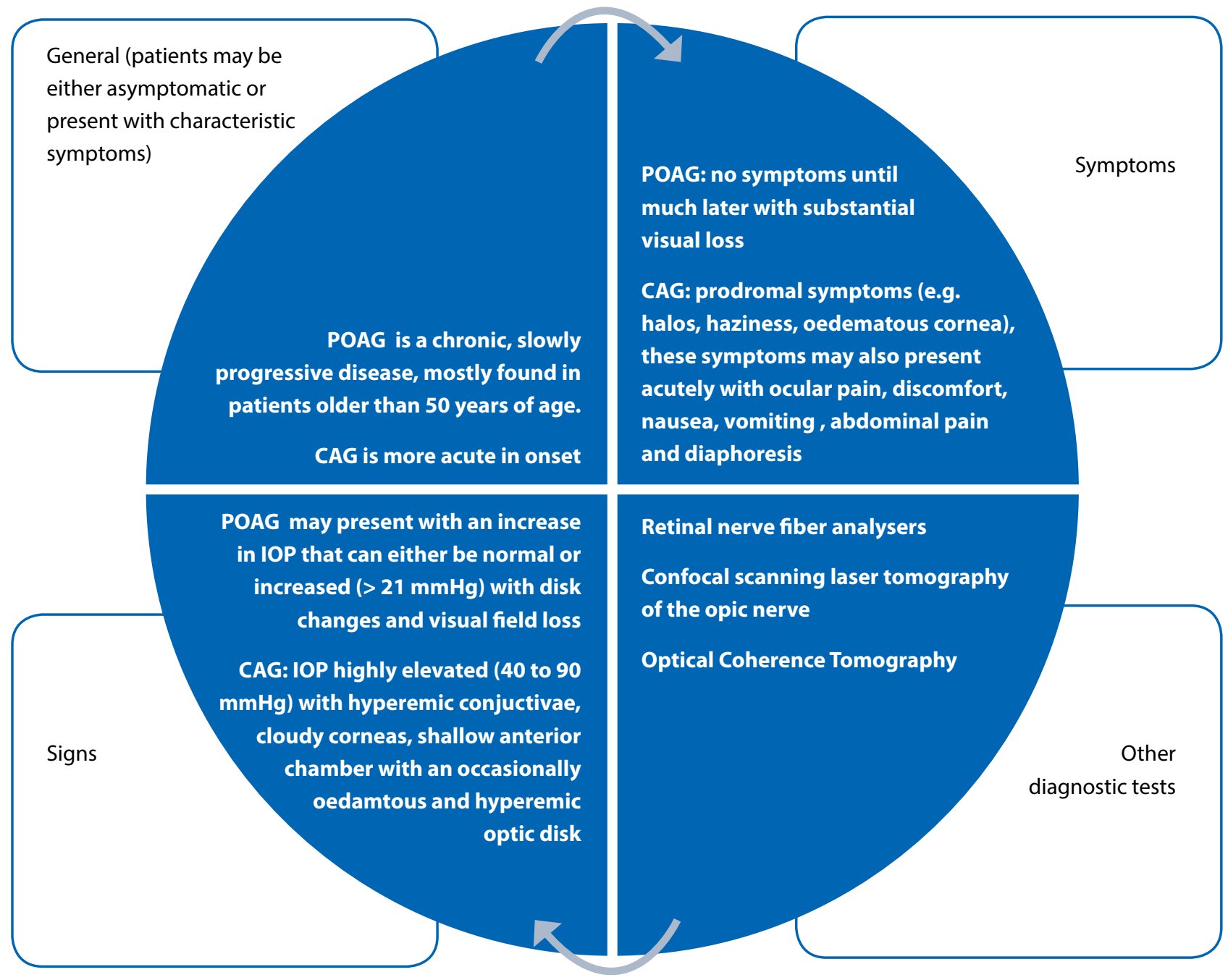

CAG: Closed-angle glaucoma; POAG: Primary open-angle glaucoma

\section{Signs, symptoms and diagnosis of glaucoma}

Differences in the time of onset between open-angle and closed-angle glaucoma are related to the pathophysiology of the condition. General differences in the clinical presentation of glaucoma are depicted in Figure 1.

\section{Risk factors for developing glaucoma}

A number of risk factors are known to be associated with glaucoma, and include the following:20-23

- Pre-existing raised intra-ocular pressure

- The risk for angle-closure glaucoma increases after the age of 40 , and the general risk for glaucoma increases after the age of 60 years

- A family history of glaucoma, especially seen in patients diagnosed with juvenile open-angle glaucoma

- Other co-morbid conditions, including diabetes mellitus, hypertension and hyperthyroidism

- Pre-existing ocular conditions, including eye tumours, retinal detachment or lens dislocation. Ocular surgery may also trigger glaucoma.
- The risk of glaucoma development and progressions increases with the degree of myopia (near-sightedness).

- The use of chronic or long-term corticosteroid therapy. This may include topical corticosteroids and other such dosage forms.

\section{The role of genetics}

Glaucoma may be an inherited disorder either through Mendelian autosomal-dominant or autosomal-recessive trait forms. Environmental factors, together with genetics, may cause multi-factorial adult-onset glaucoma, as seen in primary openangle glaucoma. Numerous genes contribute to the morphologic and biochemical features placing eyes at risk. A more thorough understanding of the genetics underlying the disorder may contribute to the future treatment of glaucoma. ${ }^{9,24}$

\section{Glaucoma treatment}

Generally speaking, it is the chronic form of open-angle glaucoma (i.e., COAG) that responds well to medical or pharmacological intervention. The first-line treatment options are considered to be monotherapy with either topical $\beta$-blockers (e.g. timolol) or prostaglandin analogues (e.g., latanoprost). Before initiation of first-line therapy, patients need to undergo a thorough 
assessment, whereby a baseline IOP measurement, as well as a target IOP goal is established. According to Weinreb et al. ${ }^{10}$ the current management guidelines from the American Academy of Ophthalmology Preferred Practice Pattern recommend lowering the IOP to a target level, which is a value or a range of values at which the clinician believes that the rate of disease progression will be slowed sufficiently to avoid functional impairment. In general, the initial target aims for a $20-50 \%$ reduction in pressure; however, the target pressure needs to be continuously reassessed during patient follow-up, depending on the progression of the disease. ${ }^{9,10}$

Treatment should ideally follow a step-wise approach, and should commence with a single agent in one of the two eyes only. This is done to establish efficacy and tolerability first, before commencing treatment of both eyes. If monotherapy with $\beta$-blockers or prostaglandin analogues are not effective to control the IOP, other agents with different mechanisms of action can be used to replace the current agent or can be added to the current treatment regime. In very severe cases where significant visual field loss has already set in, monotherapy approach may be too conservative. ${ }^{2,9,10}$

Drug therapy may also be employed in patents with other forms of glaucoma. Examples would include acute attacks of closedangle glaucoma, patients who suffer from both close-angle and concurrent primary open-angle glaucoma (POAG), and in the ophthalmic perioperative setting. A major challenge with adding multiple drops is compliance. Proper patient education regarding the correct use of topical eye preparations is crucial to ensuring adherence and treatment success. ${ }^{2,9,10}$

\section{Non-pharmacological measures}

Closed-angle glaucoma (CAG) is an ocular emergency and is stressed due to its acute presentation and need for immediate treatment. When medical treatment does not adequately reduce intraocular pressure, laser or incisional surgeries are indicated. Sometimes surgery is presented as a first-line treatment option in severe cases, in poor adherent patients or in patients with closed-angle glaucoma. Examples of the aforementioned surgical interventions are as follows: 9,10

- An iridectomy, provides the most definitive treatment option. This procedure may also be performed using a surgical laser and creates an opening in the iris through which the aqueous humour is allowed to drain more freely in a severely congested, hypertensive eye.

- Laser trabeculoplasty induces biological changes in the trabecular meshwork which causes an increase of the outflow of the aqueous humour that leads to lowering the IOP.

- Trabeculectomy is the most ordinary procedure to lower the IOP. A small section of the trabecular meshwork and or adjacent corneoscleral tissue is removed to supply a draining route for the aqueous humour from within the eye to underneath the conjunctiva where it is absorbed.

\section{Pharmacological treatment options}

The extent of the retinal ganglion cell death that is seen in glaucoma is related to the actual level that the intraocular pressure (IOP) reaches. Currently, the mainstay of glaucoma treatment is the lowering of the IOP. Every attempt should be made to achieve the patient's target IOP with the simplest possible treatment regimen. There are several different classes of IOP-lowering agents available, namely:2,10

- $\alpha$-Adrenergic agonists (examples: apraclonidine and brimonidine)

- $\beta$-Blockers (examples: betaxolol, levobunolol, timolol, etc.)

- Carbonic anhydrase (CA) inhibitors (examples: acetazolamide and dorzolamide)

- Cholinergic agonists (examples: carbachol and pilocarpine)

- Prostaglandin analogues (examples: latanoprost, travoprost, etc.)

A suitable first-line agent should also be used for patients with possible glaucoma, i.e., with ocular hypertension (IOP > 22 $\mathrm{mmHg} .^{9}$

\section{$\alpha$-Adrenergic agonists}

The two agents that are of particular importance in this group are brimonidine and apraclonidine. Both of these agents are also capable of decreasing the production of aqueous humour by the ciliary body. ${ }^{9,22}$ In addition, brimonidine is also able to achieve an increase in the rate of uveoscleral outflow. These are imidazoline drugs that activate $\alpha_{2}$-receptors in the eye and are mainly used in the acute setting due to their propensity for the development of tachyphylaxis. Both of these agents are capable of eliciting an allergic-type reaction, although apraclonidine has a much higher propensity to do so, than brimonidine. The latter is also available in a fixed-dose combination with timolol. In addition, brimonidine could also have the additional benefit of being neuroprotective to some degree. ${ }^{9,22}$

In addition to the aforementioned agents, adrenaline (epinephrine) and dipivefrin (dipivalyl epinephrine) may also be used. The latter is a prodrug of adrenaline and may thus be used in lower concentrations. These agents produce vasoconstriction and a decrease in the production of aqueous humour, however, the exact mechanism through which all of the beneficial effects of these agents in the glaucoma treatment setting manifest themselves still needs to be fully elucidated. ${ }^{25}$

\section{$\beta$-Blockers}

The following examples of ophthalmological $\beta$-adrenergic blocking agents may be used as topical treatment options, frequently as first-line therapy in the absence of specific contraindications: betaxolol, carteolol, levobunolol, metipranolol and timolol. These agents are capable of achieving a reduction in IOP of around $20-30 \% .9,22$

Differences between the five aforementioned agents are as follows:9,22 
- Timolol, levobunolol and metipranolol are non-selective $\beta$-blockers

- Betaxolol is a more specific $\beta_{1}$-receptor blocking agent (therefore its ability to lower the IOP is slightly less than that of the non-selective agents)

- Carteolol is also a non-selective $\beta$-adrenergic blocking agent, but with intrinsic sympathomimetic properties.

The mechanism through which these agents reduce the IOP is via a decrease in the production of aqueous humour by the ciliary body. This is achieved via a reduction in the concentration of cyclic adenosine monophosphate or CAMP.2,9,10,22 These agents may elicit both local and systemic adverse effects, with the latter warranting similar precautions to those that would be considered for systemic $\beta$-blocker therapy. Local adverse effects may include a stinging sensation upon instilling the drops into the eyes, as well as dry eyes, blurred vision, blepharitis and others. Systemically these agents, although used topically, could still lower the heart rate and blood pressure, and elicit bronchospasm in susceptible patients. It is therefore systemically contraindicated in patients with a history of asthma, chronic pulmonary obstructive disease or bradycardia. 2,9,10,22

\section{Carbonic anhydrase inhibitors}

Through their inhibition of the enzyme, carbonic anhydrase (CA), acetazolamide, brinzolamide and dorzolamide inhibit the production and secretion of aqueous humour by the ciliary body. This is achieved through the inhibition of the active secretion of sodium and bicarbonate ions, and the latter relates to a specific chemical reaction, namely that of carbonic acid association and dissociation (Figure 2):9,22

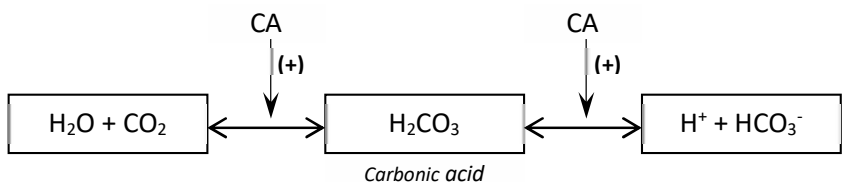

Figure 2: The carbonic acid/bicarbonate buffer system (CA: carbonic anhydrase)

Acetazolamide is the older drug in this class of therapeutic agents and is a non-selective CA-inhibitor, whereas the newer agents are more specific to the type II isozyme. Mannitol, a systemic CAI (carbonic acid anhydrase inhibitor) may be used intravenously to achieve short-term ocular hypotensive effects. ${ }^{25}$

\section{Cholinergic agonists}

Suitable agents such as pilocarpine and carbachol may be used, since the parasympathomimetic agents are capable of increasing the drainage of aqueous humour via its trabecular outflow route. This effect is achieved via muscarinic receptor stimulation on the meridional ciliary muscle fibres, which results in smooth muscle contraction with a subsequent opening of the trabecular spaces and, therefore, a decrease in the resistance to aqueous outflow. 9,22
These older-type agents have had a significant decrease in their general usefulness for the treatment of glaucoma, due to their adverse effect profile and frequent dosing requirement. Pilocarpine used to be one of the drugs of choice and can achieve a comparable drop in IOP to the $\beta$-blocking agents. ${ }^{2,9,22}$

\section{Prostaglandin analogues}

These drugs are alternative first-line agents to the $\beta$-blockers. The underlying IOP-lowering mechanism of these agents lies in the fact that they increase uveoscleral outflow, and to a lesser degree the trabecular outflow of aqueous humour as well. Important agents in this group are bimatoprost, latanoprost, tafluprost and travoprost. Latanoprost was the first of these agents approved for the topical treatment of open-angle glaucoma; they are $\mathrm{PGF}_{2 \alpha}$ (prostaglandin $\mathrm{F}_{2 \alpha}$ ) analogues that act on the prostanoid FP-receptors in the eye. Of the three agents, the prostamide (bimatoprost) has a slightly better ability to lower the IOP than the other two. 2,9,22,26

Adverse effects with these agents include hypertrichosis (excessive hair growth) around the eyes, hyperpigmentation around the eye lids and lashes, and changes in the pigmentation of the irises. These effects are, however, considered to be reversible upon discontinuation. In addition, they have been associated with uveitis as well. ${ }^{9,22,26}$ It has been shown that the prostaglandin analogues achieve a more sustained level of daynight lowering of the IOP than any other class of topical agents in the treatment of glaucoma. ${ }^{19}$

\section{Rho-kinase Inhibitor}

Glaucoma cannot always successfully be treated with $\beta$-blockers or prostaglandin analogues, due to poor responsiveness to these medications or their unwanted side-effects. Medications with novel mechanisms of action are continuously being sought. A new Rho-kinase inhibitor, ripasudil, originally used for the treatment of neuroblastoma, was recently also approved for the treatment of glaucoma in Japan. Ripasudil lowers the IOP by modulating the actin cytoskeleton and altering the conventional outflow of aqueous humour through the trabecular meshwork. 2,27,28 Ripasudil is used as addition to the existing glaucoma treatment regimen, to prevent glaucoma surgery in the short term. It can be added to existing treatment regimens regardless of the number of treatments in use. A common adverse effect is conjunctival hyperaemia, but it was shown that this complication resolved on its own within one to two hours after administration. Ripasudil drops do not interact with other eye drops in any way. ${ }^{27,28}$

\section{Conclusion}

Glaucoma, as one of the leading causes of blindness globally, may have devastating consequences if left undetected and untreated for too long. The mainstay of pharmacological intervention in glaucoma is to reduce the IOP. This may be achieved via one of two main mechanisms, namely to reduce the formation of aqueous humour, or to promote its drainage. In future, adding the new Rho-kinase inhibitor, ripasudil, to existing treatment regimens may increase the achievable level of reduction in the IOP. Patients with glaucoma should be carefully assessed 
and monitored, whilst following a step-wise approach to their treatment. It is vital that the target IOP is reached to prevent any further deterioration in a patient's visual field loss.

\section{References}

1. Arthur S, Cantor LB. Update on the role of alpha-agonists in glaucoma management. Exp Eye Res. 2011[Accessed 13 February 2017]; 93:271-83. Available from: doi: 10.1016/j.exer.2011.04.002

2. Conlon R, Saheb H, Ahmed IIK. Glaucoma treatment trends: A review. Canadian Ophthalmological Society. Published by Elsevier. 2016 [Accessed 13 February 2017]. Available from: doi: $10.1016 /$ j.jcjo.2016.07.013

3. Fraser S, Manvikar S. Glaucoma: the pathophysiology and diagnosis. Pharm J. 1 Nov 2010 [Accessed 13 February 2017]. Available from: www.pharmaceuticaljournal.com/learning/learning/11045043.article

4. Quigley $\mathrm{H}, \mathrm{Broman}, \mathrm{A}$. The number of people with glaucoma worldwide in 2010 and 2020. Br J Ophthalmol. 2006 [Accessed 13 February 2017]; 90(3):262-7. Available from: doi: 10.1136/bjo.2015.081224

5. Tham Y, Li X, Wong T, Quigley H, Aung T, Cheng C. Global prevalence of glaucoma and projections of glaucoma burden through 2040: a systematic review and meta-analysis. Ophthalmology. 2014 [Accessed 13 February 2017]; 121(11):208190. Available from: doi: 10.1016/j.ophtha.2014.05.013

6. South African Glaucoma Society (SAGS). Glaucoma algorithm and guidelines for Glaucoma. 2016 [Accessed 5 February 2017]. Available from: http://www.sags. co.za/docs/glaucoma document and algorithm.pdf

7. Glaucoma Research Foundation (GRF). Understanding glaucoma. 2016 [Accessed 5 February 2017]. Available from http://www.glaucoma.org/ glaucoma/types-of-glaucoma.php

8. Dimitriou C, Broadway D. Pathophysiology of glaucoma. Future Medicine. 2013 [Accessed 13 February 2017]; pages 32-57. Available from: doi: 10.2217/ ebo.12.421

9. Fiscella RG, Lesar TS, Edward DP. Glaucoma, in Pharmacotherapy: a pathophysiological approach. JT DiPiro, RL Talbert, GC Yee, GR Matzke, GB Wells \& LM Posey, eds. $8^{\text {th }}$ ed. New York: McGraw-Hill Medical, 2011.

10. Weinreb RN, Aung, T, Medeiros FA. The pathophysiology and treatment of glaucoma: A Review FREE. JAMA. 2014; 311(18):1901-11.

11. Coleman AL. Glaucoma. Lancet. 1999 [Accessed 13 February 2017]; 354:1803-10. Available from: doi: 10.1016/S0140-6736(99)04240-3

12. Saade CE, Lari HB, Berezina TL, Fechtner R, Khouri AS. Topical glaucoma therapy and ocular surface disease: a prospective, controlled cohort study. Can J Ophthalmol. 2015; 50(2):132-6. Available from: doi: 10.1016/j.jjjo.2014.11.006

13. Teekhasaenee C, Dorairaj S, Ritch R. Chapter Glaucoma Medical Diagnosis and Therapy. Chapter 35: Secondary Angel-Closure Glaucoma. $2^{\text {nd }}$ ed. Philadelphia: Elsevier Saunders. 2015.

14. Everitt DE, Boike SC, Piltz-Seymour JR, Van Coevorden R, Audet P, Zariffa $\mathrm{N}$, Jorkasky D. Effect of intravenous fenoldopam on intraocular pressure in ocular hypertension. J Clin Pharmacol. Apr 1997 [Accessed 13 February 2017];37(4):312-20. Available from: doi: 10.1002/j.1552-4604.1997.tb04308.x
15. Reuser T, Flanagan DW, Borland C, Bannerjee DK. Acute angle closure glaucoma occurring after nebulized bronchodilator treatment with ipratropium bromide and salbutamol. J R Soc Med. 1992; 85(8):499-500.

16. Razeghinejad MR, Pro MJ, Katz LJ. Non-steroidal drug-induced glaucoma. Eye. 2011 [Accessed 13 February 2017];25:971-80. Available from: doi: 10.1038/ eye.2011.128

17. Li J, Tripathi RC, Tripathi BJ. Drug-induced ocular disorders. Drug Safety. 2008 [Accessed 13 February 2017]; 31(2):127-41. Available from: doi: 10.2165/00002018-200831020-00003

18. Penedones A, Mendes D, Alves C, Marques FB. Drug-Induced Ocular Adverse Reactions: Review of the Safety Alerts Issued During the Last Decade. J Ocul Pharmacol Ther. 2015 [Accessed 13 February 2017]; 31(5):258-68. Available from: doi:10.1089/jop.2014.0165

19. Singh K, Shrivastava A. Medical management of glaucoma: principles and practice. Indian J Ophthalmol. 2011 [Accessed 13 February 2017]; 59(Suppl 1):S88-S92. Available from: doi: 10.4103/0301-4738.73691

20. Glaucoma Research Foundation (GRF). Understanding glaucoma. 2016 [Accessed 5 February 2017]. Available from http://www.glaucoma.org/ glaucoma/types-of-glaucoma.php

21. National Eye Institute (NEI). Facts about glaucoma. [Accessed on 5 February 2017]. Available from https://www.nei.nih.gov/health/glaucoma/glaucoma_facts

22. Brenner GM, Stevens CW. Pharmacology. $4^{\text {th }}$ ed. Philadelphia: Elsevier Saunders. 2013.

23. McMonnies CW. Glaucoma history and risk factors. J Optom. 2016 [Accessed 13 February 2017]; 184:1-8. Available from: doi: 10.1016/j.opton.2016.02.003

24. Ahram DF, Alward WL, Kuehn MH. The genetic mechanisms of primary angle closure glaucoma. Eye. 2015 [Accessed 13 February 2017]; 29:1251-9. Available from: doi: 10.1038/eye.2015.124

25. Rossiter D. South African medicines formulary. $10^{\text {th }}$ ed. Rondebosch: Health and Medical Publishing Group, 2012.

26. Alm A. Latanoprost in the treatment of glaucoma. Clin Ophthalmol. 2014 [Accessed 13 February 2017]; 8:1967-85. Available from: doi 10.2147/OPTH. S59162

27. Inazaki H, Kobayashi S, Anzai Y, Satoh H, Sato S, Inoue M, et al. Efficacy of the Additional Use of Ripasudil, a Rho-Kinase Inhibitor, in Patients with Glaucoma Inadequately Controlled Under Maximum Medical Therapy. Wolters Kluwer Health, Inc. 2016 [Accessed 13 February 2017]; 26:96-100. Available from: doi 10.1097/s1079/JJG.0000000000000552

28. Inoue K, Okayama R, Shiokawa M, Ishida K, Tomita G. Efficacy and safety of adding ripasudil to existing treatment regiments for reducing intraocular pressure. Int Ophthalmol. 2017 [Accessed 13 February 2017]. Available from: doi 10.1007/s10792-019-0427-9

29. OCSA. World glaucoma week. c2014 [Accessed 5 February 2017]. Available from: http://www.ocsa.co.za/wp-content/uploads/2014/06/Glaucoma-HealthBytes-2012.pdf 